\title{
NUCLEAR POWER ENGINEERING EDUCATION PROGRAM- UNIVERSITY OF ILLINOIS
}

\author{
Progress Report \\ First Year Activities \\ May 15, 1992 to March 31, 1993
}

\section{Year One Accomplishments}

The funding for the first year of the program was concentrated in three main areas: Reactor Console Upgrade, Nuclear Engineering Undergraduate Laboratory Upgrade, and the development of an Instructional Computational Laboratory. Smaller amounts of initial funding were directed to student recruitment and retention, faculty development, and bridges with the nuclear power industry. The three main areas are described first:

\section{Reactor Console Upgrade}

Three years ago a program to replace the original analog control console on the Illinois Advanced TRIGA Reactor with a modern digital/CRT display unit was initiated. Several sources of funding were combined to meet the $\$ 420,000$ total cost involved, and included government, industry and university components. Commonwealth Edison was one of the contributors. They specifically designated that their $\$ 50,000$ component of the first year funding of the DOE-CECo pilot program to our nuclear engineering department was to be used to complete their contribution to the console procurement. This was done and was reflected in our first year budget.

The new console will enable extension of our operator training program which is utilized by the nuclear power utilities to augment their operator training. In particular, the use of the simple and responsive TRIGA reactor to study and observe a wide variety of reactivity effects on critical systems is beneficial to improving operator understanding of reactivity management. The new console was installed in March, 1993 and in undergoing initial operation trials now (3/30/93).

\section{Nuclear Engineering Undergraduate Laboratory Upgrade}

At present, undergraduate nuclear engineers at the University of Illinois are required to take 4 semester hours of laboratory course work. These 4 semester hours are comprised of 3 semester hours of NE 351, Radiation Detection and Measurements Laboratory (presently Nuclear Engineering Laboratory), see Table 1, and 1 semester hour of NE 352, Nuclear Engineering Laboratory (presently Advanced Nuclear Engineering Laboratory), see Table 2. These laboratories comprise experiments which represent common experience for all undergraduate nuclear engineers, and are also available to graduate students who have no previous background in those areas.

These laboratories are the core of the undergraduate laboratory experience, and concentrate on concepts and techniques which are critical to the full understanding of the principles of nuclear power engineering, and are commonly associated with nuclear 
instrumentation, reactor operations and monitoring, and ancillary principles such as shielding and health physics. Presently the teaching of these laboratories is limited by the equipment available to run the laboratory experiments efficiently. Often only one laboratory set-up is available for each experiment, and student groups must be juggled from week to week to have access to the equipment. Equipment for these laboratories is expensive.

Funds from the first year were used to purchase additional equipment for the NE 351 laboratory in order to make available multiple laboratory set-ups. This has started to alleviate bottlenecks with equipment availability and has produced a much more efficient laboratory course.

In addition, one half-time graduate student was employed during the Summer 1992 Session to implement the new equipment acquisition and to document the changes in equipment configuration and usage. Additional students were employed in the Spring 1993 Semester to support laboratory and other power-related development.

\section{Nuclear Engineering Instructional Computing Laboratory}

Certain advances in laboratory capabilities have served to reduce the demands on students and teachers, while providing the students with an enhanced laboratory experience. Principal among these is the application of desk top computers both for data acquisition and for data analysis. The use of PC-based data handling allows for much more efficient data acquisition while providing students with computer aperience beyond that available from lower level undergraduate computer programing courses.

In addition to their use for data acquisition and analysis, the availability of desk top computers also allows their use for "computational experiments" in which openended experiments are performed as computation exercises. This is consistent with a growing number of advanced research investigations where the results of interest are obtained by formulating models of complex phenomena and systems, and evaluating their behavior via large computational programs, many of which enable on-line interaction by the investigator. This is especially applicable in cases where nonlinear phenomena and/or large systems of coupled equations are involved as represented by computational models of nuclear power plant behavior and performance. In these cases, it is typically not possible a priori to ascertain the results of interest; these are found only by running the program, i.e., the numerical computation. In many fields these procedures are eliminating, or at least reducing, the need for detailed physical experiments. A nuclear engineering interactive computing laboratory presently exists, NE 390B, Nuclear Engineering Interactive Computing Laboratory (4 semester hours, see Table 3), and underlying computational aspects are presently a part of other nuclear engineering courses, principally, NE 312, Nuclear Power Economics and Fuel Management, NE 331, Materials in Nuclear Engineering, NE 342, Radioactive Waste Management.

Equipment for these computational applications was purchased with funds from this program to further develop nuclear engineering instructional computing laboratories, and to coordinate data acquisition and processing from the experimental laboratories described above. This computational equipment was in the form of a 486based network server, up to four 486-based PC workstations for computational work, and ancillary facilities. This allows the use of other existing 286-based PC's for use in the experimental laboratory setting, and these will also be networked. Through the network server and campus fibre optic backbone, these computers will communicate 
with major computing facilities on campus, including several workstation laboratories in the College of Engineering.

\section{Other Programs}

In adcition to the projects described above, other smaller amounts of funds were directed to the following projects to enhance nuclear power education.

Some funds were used for the recruitment and retention of top quality graduate students in the nuclear power area. These funds were use for nuclear power graduate stipend enhancements (e.g. $\$ 1000$ to deserving candidates), support for campus visits to attract top students to Illinois to graduate school, and funds for Illinois faculty to visit other Universities and Junior Colleges to interview and attract top students.

\section{DISCLAIMER}

\footnotetext{
This report was prepared as an account of work sponsored by an agency of the United States Government. Neither the United States Government nor any agency thereof, nor any of their employees, makes any warranty, express or implied, or assumes any legal liability or responsibility for the accuracy, completeness, or usefulness of any information, apparatus, product, or process disclosed, or represents that its use would not infringe privately owned rights. Reference herein to any specific commercial product, process, or service by tradc name, trademark, manufacturer, or otherwise does not necessarily constitute or imply its endorsement, recommendation, or favoring by the United States Government or any agency thereof. The views and opinions of authors expressed herein do not necessarily state or reflect those of the United States Government or any agency thereof.
} 
Table 1

NE 351, Radiation Detection and Measurements Laboratory Laboratory Experiments

\section{Experiments}

1. Nuclear Instrumentation( 2 weeks)

2. Geiger-Muller Counter(1 weeks)

3. Radiation Detection and Counting Statistics

( 2 weeks)

4. Gamma Attenuation(2 weeks)

5. Health Physics(1 week)

6. Heat Transfer(1 week)

7. Semiconductor Spectrometry(2 weeks)

8. Shielding( 1 week)

9. Neutron Cross Sections(1 week)

Table 2

NE 352, Nuclear Engineering Laboratory

Laboratory Experiments

Experiments

1. Reactor Operations ( 2 weeks)

Instrumentation, Multiplication Factor and Reactivity, Reactivity Worth,

Temperature Coefficient

2. Subcritical Experiment (1 week)

Material Buckling, Critical Size

3. DC Glow Discharge (2 weeks)

Plasma Properties, Debye Shielding, Langmuir Probe, Plasma Diffusion 
Table 3

NE 390B, Nuclear Engineering Interactive Computing Laboratory Laboratory Experiments

Experiments

1. Numerical Linear Algebra(2 weeks)

1.1 Matrix Multiplication and Power Method for the Computation of the Dominant Eigenvalue of a Matrix

1.2 Numerical Solution of Systems of Algebraic Equations

1.3 Computation of Eigenvalues and Eigenvectors

1.4 Tridiagonal Solvers

2. Finite Difference Simulations for the Inhomogeneous Diffusion Equation(4 weeks)

2.1 Standard Difference Equations

2.2 Exact Difference Equations

2.3 Combined Integral Transform-Exact Difference Equation Formulation for Multidimensional Problems

3. Comparison of Effective Multiplication Factors Computed with One-Group Diffusion Theory and One-Group Transport Theory(1 week)

4. Comparison of Effective Multiplication Factors for Bare Fast Reactors Computed with One-, Two-, and Three-Group Diffusion Data from ANL- 5800 and Ten-Group Transport Theory Data from Los Alamos(2 weeks)

5. Numerical Solutions of Systems of Ordinary Differential Equations and Initial Value Problems

5.1 Fourth Order Runge-Kutta Method

5.2 Fourth Order Adams-Bashforth-Moulton Method

5.3 Applications to Motion of Charged Particles in Electromagnetic Fields and Radioactive Decay Chains

6. Finite Element Method for Linear and Nonlinear Heat Conduction(2 weeks)

6.1 Steady-state Temperature Fields in Reactor Components

6.2 Transient Temperature Fields in Reactor Components

7. Advanced Special Topics (Examples Follow) (2 weeks)

7.1 Numerical Computation of Green's Functions and Green's Dyadics

7.2 Double-sweep Method for Two-point Boundary Value Problems

7.3 Numerical Solution of Integral Equations

7.4 Group Invariant Difference Schemes

7.5 Numerical Hydrodynamics 


\begin{abstract}
The DOE/CECo Nuclear Power Engineering Education Program at the University of Illinois in its first year has significantly impacted the quality of the power education which our students receive. It has contributed to: the recently completed upgrade of the console of our Advanced TRIGA reactor which increases the reactor's utility for training, the procurement of new equipment to upgrade and refurbish several of the undergraduate laboratory set-ups, and the procurement of computational workstations in support of the instructional computing laboratory. In addition, smaller amounts of funds were used for the recruitment and retention of top quality graduate students, the support of faculty to visit other institutions to attract top students into the discipline, and to provide funds for faculty to participate in short courses to improve their skills and background in the power area. These items and activities have helped elevate in the student's perspective the role of nuclear power in the discipline. We feel this is having a favorable impact on student career selection and on ensuring the continued supply of well educated nuclear engineering graduates.
\end{abstract}



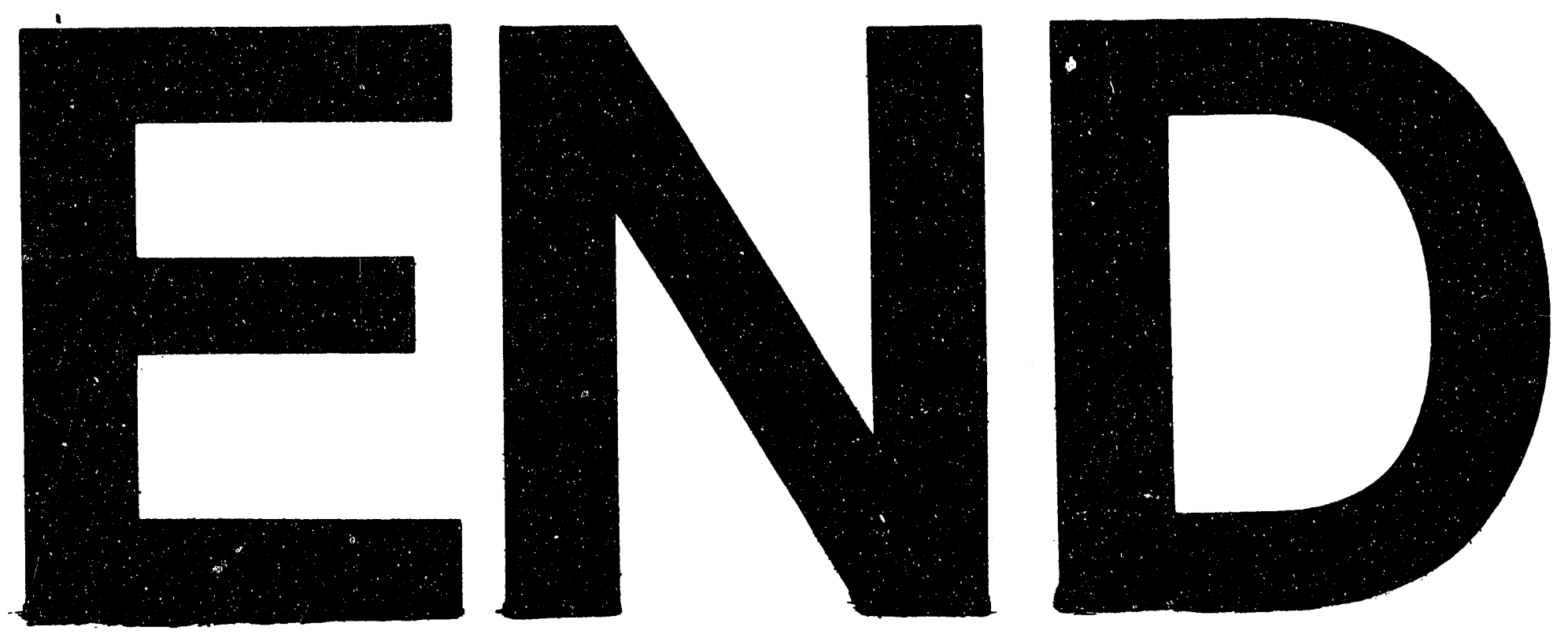

2

20
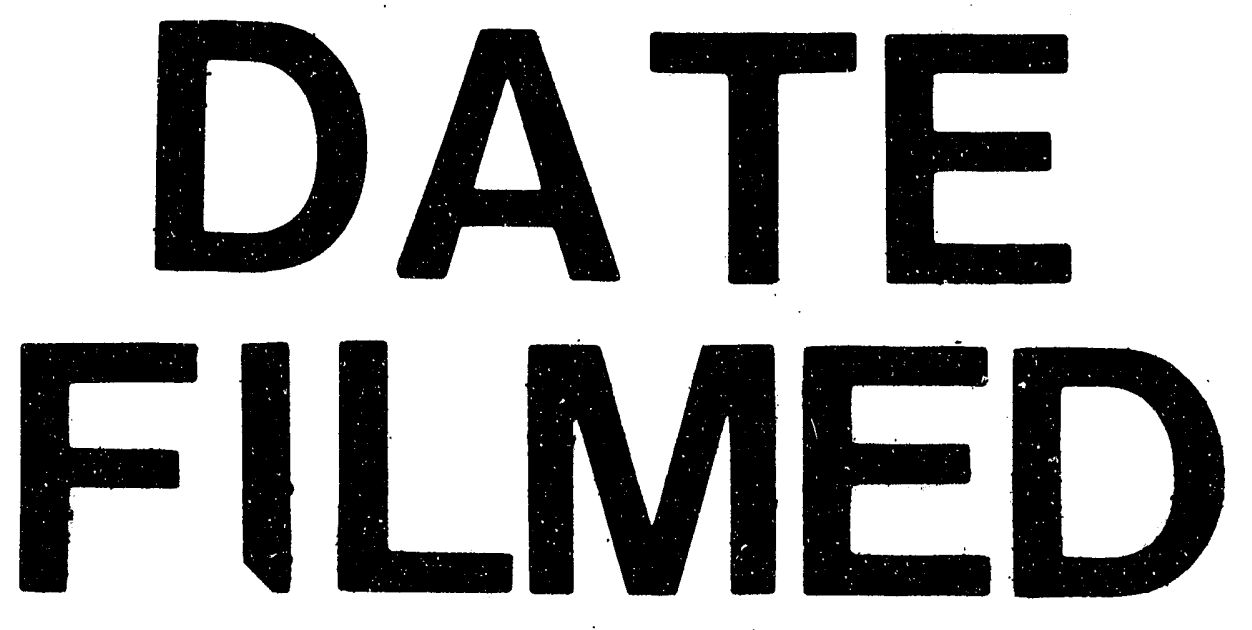

$6|24| 93$

豆 
